\title{
Reducing exercise-induced muscular injury in kendo athletes with supplementation of coenzyme $Q_{10}$
}

\author{
Michihiro Kon ${ }^{1}$, Kai Tanabe ${ }^{1}$, Takayuki Akimoto ${ }^{2}$, Fuminori Kimura ${ }^{1}$, Yuko Tanimura ${ }^{1}$, Kazuhiro Shimizu ${ }^{1}$, \\ Tadashi Okamoto ${ }^{3}$ and Ichiro Kono ${ }^{1 *}$ \\ ${ }^{1}$ Graduate School of Comprehensive Human Sciences, Doctoral program of Sports Medicine, University of Tsukuba, \\ 1-1-1 Tennodai, Tsukuba, Ibaraki 305-8574, Japan \\ ${ }^{2}$ Division of Biomedical Materials and Systems, Center for Disease Biology and Integrative Medicine, Faculty of Medicine, \\ University of Tokyo, 7-3-1Hongo, Bunkyo, Tokyo 113-0033, Japan \\ ${ }^{3}$ Department of Biochemistry, Faculty of Pharmaceutical Sciences, Kobe Gakuin University, Nishi-ku, Kobe, \\ Hyogo 651-2180, Japan
}

(Received 10 September 2007 - Revised 6 December 2007 - Accepted 8 January 2008 - First published online 20 February 2008)

Intensive physical exercise may cause muscular injury and increase oxidative stress. The purpose of this study was to examine the effect of an antioxidant, coenzyme $\mathrm{Q}_{10}\left(\mathrm{CoQ}_{10}\right)$, on muscular injury and oxidative stress during exercise training. Eighteen male students, all elite Japanese kendo athletes, were randomly assigned to either a $\mathrm{CoQ}_{10}$ group $(n 10)$ or a placebo group $(n 8)$ in a double-blind manner. Subjects in the $\mathrm{CoQ}_{10}$ group took $300 \mathrm{mg} \mathrm{CoQ}_{10}$ per $\mathrm{d}$ for $20 \mathrm{~d}$, while subjects in the placebo group took the same dosage of a placebo. All subjects practised kendo $5.5 \mathrm{~h}$ per $\mathrm{d}$ for $6 \mathrm{~d}$ during the experimental period. Blood samples were taken 2 weeks before, during $(1 \mathrm{~d}, 3 \mathrm{~d}, 5 \mathrm{~d})$ and 1 week after the training. Serum creatine kinase $(\mathrm{CK})$ activity and myoglobin $(\mathrm{Mb}$ ) concentration significantly increased in both groups (at $3 \mathrm{~d}$ and $5 \mathrm{~d}$ ). Serum $\mathrm{CK}$ (at $3 \mathrm{~d}$ ), Mb (at $3 \mathrm{~d}$ ) and lipid peroxide (at $3 \mathrm{~d}$ and $5 \mathrm{~d}$ ) of the $\mathrm{CoQ}_{10}$ group were lower than those of the placebo group. The leucocyte counts in the placebo group significantly increased (at $3 \mathrm{~d}$ ) and neutrophils significantly increased in both groups (at $3 \mathrm{~d}$ and $5 \mathrm{~d}$ ). Serum scavenging activity against superoxide anion did not change in either group. These results indicate that $\mathrm{CoQ}_{10}$ supplementation reduced exercise-induced muscular injury in athletes.

coenzyme $\mathbf{Q}_{10}$ : Muscular injury: Oxidative stress: Kendo

Coenzyme $\mathrm{Q}_{10}\left(\mathrm{CoQ}_{10}\right)$, also known as ubiquinone, is a lipidsoluble, vitamin-like substance located in the hydrophobic interior of the phospholipid bilayer of the cellular membrane. $\mathrm{CoQ}_{10}$ increases mitochondrial activity related to the synthesis of $\mathrm{ATP}^{(1)}$. In addition, $\mathrm{CoQ}_{10}$ acts as an antioxidant in both the mitochondria and lipid membranes by scavenging reactive oxygen species (ROS), either directly or in conjunction with $\alpha$-tocopherol ${ }^{(2-5)}$. This antioxidant activity appears only with the reduced form (ubiquinol). The oxidized form (ubiquinone) is readily reduced to ubiquinol enzymically after dietary uptake $^{(6)}$. Although $\mathrm{CoQ}_{10}$ is present in meat and fish, its content in such foods is very low ${ }^{(7)}$. Therefore, synthetic $\mathrm{CoQ}_{10}$ is used as a dietary supplement by both health-conscious individuals and those with ailments because of its important biological roles, such as mitochondrial energy metabolism and antioxidant activity ${ }^{(8)}$.

Aerobic energy production generates ROS in muscle cells, and the amount of ROS increases approximately 10- to 20-fold during physical exercise ${ }^{(9)}$. Evidence exists to suggest that ROS induce muscular injury ${ }^{(10-12)}$ with a subsequent decrease in physical performance ${ }^{(13)}$. Recent research has suggested that supplementation with certain antioxidants is practical for physically active individuals to hasten recovery from fatigue and to prevent exercise damage ${ }^{(14)}$. Supplementations with other antioxidant nutrients, such as vitamin $\mathrm{C}$ and vitamin $\mathrm{E}$, can prevent exercise-induced oxidative damage in human subjects and rats ${ }^{(15,16)}$. However, little is known about the effect of $\mathrm{CoQ}_{10}$ supplementation on muscular injury and oxidative stress resulting from strenuous exercise in human subjects.

Shimomura et al. ${ }^{(17)}$ reported that intravenous $\mathrm{CoQ}_{10}$ supplementation attenuates the rise in markers of muscle damage in rats following downhill running. In addition, Okamoto et al. ${ }^{(18)}$ provided evidence that $\mathrm{CoQ}_{10}$ protects cultured skeletal muscle cells from electrical stimulation-induced lactate dehydrogenase release. From these experimental results, $\mathrm{CoQ}_{10}$ supplementation may have the potential to reduce exercise-induced muscular cell damage and oxidative stress in human individuals.

Kendo is a traditional Japanese sport and involves duelling between two people who are each equipped with protective armour and a sword-like stave made of bamboo. A match may last up to $5 \mathrm{~min}$ and the winner is the first to score the second

Abbreviations: CK, creatine kinase; $\mathrm{COQ}_{10}$, Coenzyme $\mathrm{Q}_{10}$; ESR, electron spin resonance; LPO, lipid peroxide; Mb, myoglobin; ROS, reactive oxygen species; WBC, leucocyte.

* Corresponding author: Dr Ichiro Kono, fax +81 29853 2656, email kono@taiiku.tsukuba.ac.jp 
of a maximum three points. Points are scored by inflicting blows to the head, torso, forearm or throat. Some previous studies including our own have shown that kendo exercise in training camp is a highly intense exercise that causes an increase of oxidative stress and cellular damage ${ }^{(19-21)}$. The purpose of the present study, then, was to examine the effect of $\mathrm{CoQ}_{10}$ supplementation on the exercise-induced muscular injury and oxidative stress of collegiate kendo athletes during training camp. We hypothesized that $\mathrm{CoQ}_{10}$ supplementation would reduce exercise-induced muscular damage and oxidative stress. To test this hypothesis, we investigated the time course changes of muscular damage and oxidative stress markers in kendo athletes during training camp.

\section{Materials and methods}

\section{Subjects}

Eighteen male students of the University of Tsukuba, all elite Japanese kendo athletes, participated in a $6 \mathrm{~d}$ training camp from 25 to 30 March 2006. The characteristics of the subjects are shown in Table 1. All subjects completed a medical and supplementation history questionnaire so we could determine their eligibility for the study. No subjects used anti-inflammatory drugs or dietary supplements during this study. The experimental procedure was approved by the Human Research Ethics Committee of Tsukuba University and was explained to the subjects before they signed informed consent forms.

\section{Treatment}

All subjects were randomly assigned to either a $\mathrm{CoQ}_{10}$ supplemented group $(n 10)$ or a placebo supplemented group ( $n$ 8) in a double-blind manner. Subjects in the $\mathrm{CoQ}_{10}$ group took three Kaneka $\mathrm{CoQ}_{10} 100 \mathrm{mg}$ capsules once per d, in the morning after breakfast, from $14 \mathrm{~d}$ before the training camp started until it ended. Subjects in the placebo group consumed three placebo capsules per $\mathrm{d}$ for the same duration. Both the $\mathrm{CoQ}_{10}$ and placebo were identical in appearance. Also, all subjects ate the same diet during the training camp.

\section{Composition of Kaneka $Q_{10}$ capsules}

The $\mathrm{CoQ}_{10}$ capsules used in the present study were provided by the Kaneka Corporation (Osaka, Japan). Each capsule contained $100 \mathrm{mg}$ Kaneka $\mathrm{CoQ}_{10}, 0.4 \mathrm{mg}$ lecithin SLP-Paste NGS (Tsuji Oil Mill, Mie, Japan), $134.67 \mathrm{mg}$ safflower oil (Nisshin Oillio Group, Tokyo, Japan), 0.6 mg Poem S-100V (Riken Vitamin,
Tokyo, Japan) and 4.33 mg yellow beeswax (Miki Chemical Industry, Hyogo, Japan). The placebo capsules were the same, except they contained safflower oil instead of $\mathrm{CoQ}_{10}$.

\section{Exercise protocol}

During the camp, there were two separate training sessions on each day: $2.5 \mathrm{~h}(09.00-11.30$ hours) in the morning and $3 \mathrm{~h}$ (14.30-17.30 hours) in the afternoon. There was no morning session on the first day of the training camp. Morning practices consisted of $20 \mathrm{~min}$ warming-up, $40 \mathrm{~min}$ kihonkeiko (practising to acquire the basic movements), a $10 \mathrm{~min}$ break, $60 \mathrm{~min}$ gokaku-keiko (keiko practised by persons of almost equal skill), 15 min kakari-keiko (the keiko method in which, for a short time period, the trainee practises striking the motodachi, the person acting as instructor, with all learned waza techniques without thinking of being struck or of dodging strikes) and 5 min cooling down. Afternoon practices consisted of $20 \mathrm{~min}$ warming-up, $100 \mathrm{~min}$ shiai-keiko (a method of keiko performed in the presence of referees, as in a match), a $10 \mathrm{~min}$ break, $45 \mathrm{~min}$ gokaku-keiko and 5 min cooling down. The $\mathrm{VO}_{2 \max }$ percentages were approximately 40 for kihon-keiko, approximately 55 for gokakukeiko and approximately 70 for kakari-keiko. The $\mathrm{VO}_{2 \max }$ percentage for shiai-keiko at its maximum value was also approximately $70^{(19)}$.

\section{Blood sampling}

A $20 \mathrm{ml}$ venous blood sample was obtained from each athlete's forearm in a resting condition between 13.30 and 14.15 hours every afternoon: 2 weeks before the training camp (pre), first day ( $1 \mathrm{~d})$, third day (3d), fifth day (5d) and 1 week after the camp (post). Serum was separated from blood cells by centrifugation (3000 rpm for $10 \mathrm{~min}$ ) and stored at $-30^{\circ} \mathrm{C}$ until analysis. Serum volume was adjusted according to Dill and Costill's equation ${ }^{(22)}$.

\section{Biochemical analysis}

Creatine kinase (CK) activity in the serum, as a marker of muscle damage, was measured by using a commercial kit (Kanto Chemical Co., Tokyo, Japan). Another marker of muscle damage, serum myoglobin $(\mathrm{Mb})$ concentration, was determined by using a commercial kit (Eiken Chemical Co., Tokyo, Japan). Counts of leucocytes (WBC), neutrophil cells and monocyte cells were obtained using an automated cell counter (SE-9000; Sysmex, Kobe, Japan). Serum lipid peroxide (LPO), which is

Table 1. Characteristics of the subjects*

(Mean values and standard deviations)

\begin{tabular}{|c|c|c|c|c|c|c|c|c|c|c|}
\hline \multirow[b]{2}{*}{ Study groups } & \multicolumn{2}{|c|}{ Age (years) } & \multicolumn{2}{|c|}{ Height (cm) } & \multicolumn{2}{|c|}{ Weight (kg) } & \multicolumn{2}{|c|}{$\%$ fat } & \multicolumn{2}{|c|}{$\begin{array}{c}\text { Athletic career } \\
\text { (years) }\end{array}$} \\
\hline & Mean & $\mathrm{SD}$ & Mean & SD & Mean & $\mathrm{SD}$ & Mean & SD & Mean & SD \\
\hline $\mathrm{CoQ}_{10}$ & $20 \cdot 5$ & 1.0 & $171 \cdot 3$ & $5 \cdot 8$ & $71 \cdot 3$ & 8.0 & 14.5 & $2 \cdot 4$ & $13 \cdot 8$ & $1 \cdot 3$ \\
\hline Placebo & $19 \cdot 6$ & 1.0 & $172 \cdot 7$ & $5 \cdot 8$ & 71.9 & $8 \cdot 3$ & 14.5 & 1.9 & $12 \cdot 5$ & 1.9 \\
\hline
\end{tabular}

$\mathrm{CoQ}_{10}$, coenzyme $\mathrm{Q}_{10}$.

* For details of subjects and procedures, see Materials and methods. 
an index of oxidative stress concentration, was determined by using a commercial kit (Kyowa Medex Co., Tokyo, Japan). Serum concentration of $\mathrm{CoQ}_{10}$ was measured by HPLC, a method described in Ikematsu et al. ${ }^{(23)}$.

Electron spin resonance measurement of scavenging activity against superoxide

Scavenging activity against superoxide was measured using the method described by Tanabe et al. ${ }^{(24)}$. The serum scavenging activity against superoxide anions derived from the xanthine oxidase-hypoxanthine reaction was determined by calculating the inhibition rate of electron spin resonance (ESR) (JES-TE25X; JEOL, Tokyo, Japan) signals in a mixture of serum and a superoxide-generating system. For measuring the scavenging activity against superoxide the reaction mixture consisted of $50 \mu \mathrm{l}$ serum, 5.5 mM-hypoxanthine (6-hydroxypurine), $0.4 \mathrm{U} / \mathrm{ml}$ xanthine oxidase and $15 \mu l$ 9.2 M-5,5-dimethyl-1-pyrroline- $N$-oxide as a spin trap agent. The ESR spectra were recorded $45 \mathrm{~s}$ after xanthine was added at room temperature. The blank spectrum was considered as a control and the standard curve of superoxide dismutase activity was constructed based on the spectra with $6 \cdot 25,12 \cdot 5,25$ and $50 \mathrm{U} / \mathrm{ml}$ superoxide dismutase ${ }^{(24)}$. Signal intensity was expressed as a ratio of the peak located at the lowest magnetic field of the four-line 5,5-dimethyl-1-pyrroline- $N$-oxide-superoxide adduct signal to the signal intensity of internal standard $\mathrm{Mn}^{2+}$. Scavenging activity was calculated as SOD activity based on the standard curve ${ }^{(24)}$.

\section{Statistics}

All data were analysed by a two-way ANOVA with repeated measures using StatView 5.0 (Hulinks, Tokyo, Japan). If significant differences existed, a posthoc analysis test (Bonferroni/Dunn) was performed. The percent changes between the groups were compared using unpaired $t$ tests. The level of statistical significance was set at $P<0 \cdot 05$.

\section{Results}

Weight and body fat

Weight and body fat remained unchanged in both the $\mathrm{CoQ}_{10}$ and placebo groups over the training period (data not shown).

\section{Serum coenzyme $Q_{10}$ concentration}

Fig. 1 shows serum $\mathrm{CoQ}_{10}$ concentration data before (pre) and during $(1 \mathrm{~d}$ and $5 \mathrm{~d})$ the training camp. In the $\mathrm{CoQ}_{10}$ group, serum $\mathrm{CoQ}_{10}$ concentration significantly increased $(P<0 \cdot 01)$ in 2 weeks (from pre to $1 \mathrm{~d}$ ). On the other hand, serum $\mathrm{CoQ}_{10}$ concentration in the placebo group did not change from pre to $5 \mathrm{~d}$. Percent changes in serum $\mathrm{CoQ}_{10}$ concentration in the $\mathrm{CoQ}_{10}$ group were higher than those of the placebo group at $1 \mathrm{~d}$ and $5 \mathrm{~d}(P<0.01)$. Therefore, our finding was that oral supplementation with $\mathrm{CoQ}_{10}$ for 2 weeks significantly increases serum $\mathrm{CoQ}_{10}$ level.

\section{Serum creatine kinase activity}

Fig. 2 shows serum CK activity data before (pre), during ( $1 \mathrm{~d}$, $3 \mathrm{~d}, 5 \mathrm{~d}$ ) and after (post) training camp. In both the $\mathrm{CoQ}_{10}$ and

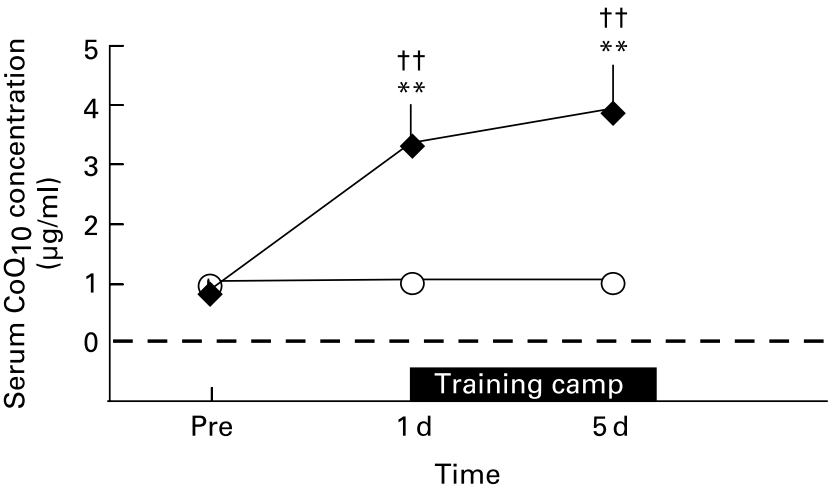

Fig. 1. Serum coenzyme $Q_{10}\left(C_{o} Q_{10}\right)$ concentration before (pre) and during $(1 \mathrm{~d}$ and $5 \mathrm{~d})$ training camp $\left(-\bullet-, \mathrm{CoQ}_{10} ;-\mathrm{O}-\right.$, placebo). Values are means and standard deviations. Mean values were significantly different from pre: ${ }^{\star *} P<0 \cdot 01$. Mean values were significantly different between $\mathrm{CoQ}_{10}$ and placebo groups: $\dagger \dagger P<0.01$.

placebo groups, serum $\mathrm{CK}$ activity significantly increased at $3 \mathrm{~d}$ and $5 \mathrm{~d}$ compared with pre $(P<0 \cdot 01)$. Percent changes in serum $C K$ activity in the $\mathrm{CoQ}_{10}$ group were significantly lower than those of the placebo group at $3 \mathrm{~d}(P<0 \cdot 05)$. This result suggests that supplementation of $\mathrm{CoQ}_{10}$ reduced exercise-induced muscular injury in athletes.

\section{Serum myoglobin concentration}

Fig. 3 shows serum Mb concentration data before (pre), during $(1 \mathrm{~d}, 3 \mathrm{~d}, 5 \mathrm{~d})$ and after (post) training camp. In both the $\mathrm{CoQ}_{10}$ and placebo groups, serum $\mathrm{Mb}$ concentration significantly increased at $3 \mathrm{~d}$ and $5 \mathrm{~d}$ compared with pre $(P<0 \cdot 01)$. Percent changes of serum $\mathrm{Mb}$ concentration in the $\mathrm{CoQ}_{10}$ group were significantly lower than those of the placebo group at $3 \mathrm{~d}$ $(P<0.05)$. This data is further evidence that $\mathrm{CoQ}_{10}$ reduced exercise-induced muscular injury.

\section{Serum lipid peroxide concentration}

Fig. 4 shows serum LPO concentration data before (pre), during ( $1 \mathrm{~d}, 3 \mathrm{~d}, 5 \mathrm{~d})$ and after (post) training camp. LPO concentration did not change in either group. Percent changes of serum LPO concentration in the $\mathrm{CoQ}_{10}$ group were lower than

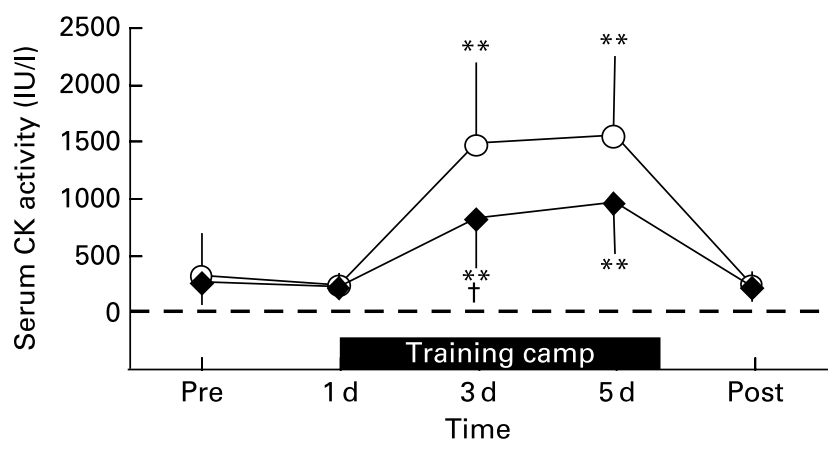

Fig. 2. Serum creatine kinase (CK) activity before (pre), during (1d, $3 d, 5 d)$, and after (post) training camp (- - , coenzyme $Q_{10} ;-O-$, placebo). Values are means and standard deviations. Mean values were significantly different from pre: ${ }^{\star \star} P<0.01$. Mean values were significantly different between coenzyme $Q_{10}$ and placebo groups: $† P<0.05$. 


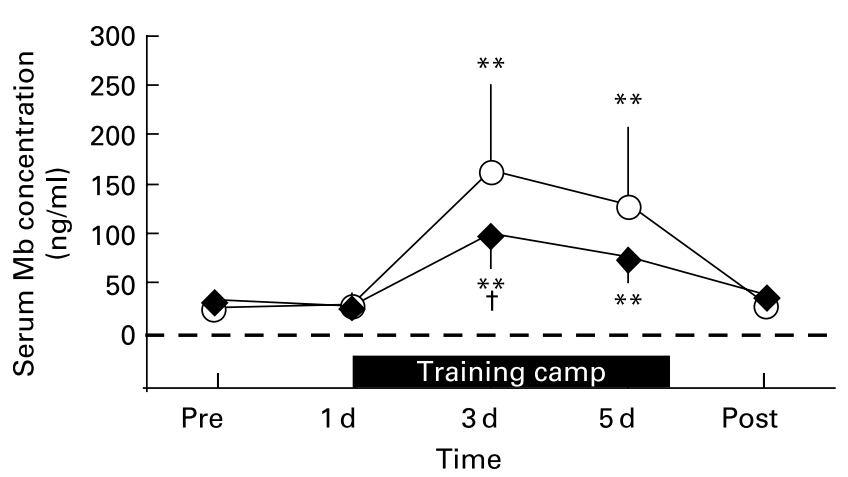

Fig. 3. Serum myoglobin (Mb) concentration before (pre), during ( $1 \mathrm{~d}, 3 \mathrm{~d}$, $5 \mathrm{~d})$ and after (post) training camp (- - , coenzyme $\mathrm{Q}_{10} ;-\bigcirc-$, placebo). Values are means and standard deviations. Mean values were significantly different from pre: ${ }^{\star \star} P<0.01$. Mean values were significantly different between coenzyme $Q_{10}$ and placebo groups: $\dagger P<0.05$.

those of the placebo group at $3 \mathrm{~d}$ and $5 \mathrm{~d}(P<0 \cdot 05)$. Therefore, in the present study, the effect of $\mathrm{CoQ}_{10}$ supplementation on exercise-induced oxidative stress in athletes was unclear.

\section{Leucocytes, neutrophil cells and monocyte cells}

Table 2 shows WBC, neutrophil and monocyte data before (pre), during ( $1 \mathrm{~d}, 3 \mathrm{~d}, 5 \mathrm{~d})$ and after (post) training camp. In the placebo group, the WBC count significantly increased at $3 \mathrm{~d}$ compared with pre $(P<0 \cdot 01)$. In contrast, WBC did not change in the $\mathrm{CoQ}_{10}$ group. The neutrophil count in both groups also significantly increased at $3 \mathrm{~d}$ and $5 \mathrm{~d}$ compared with pre $(P<0.05)$, whereas monocyte count did not change in either group. WBC, neutrophil and monocyte counts did not differ significantly between the $\mathrm{CoQ}_{10}$ and placebo groups. Therefore, these results suggested that oral supplementation with $\mathrm{CoQ}_{10}$ has no effect on the changes of WBC, neutrophil and monocyte.

\section{Scavenging activity against superoxide anion}

Fig. 5 shows serum scavenging activity against superoxide anion data before (pre), during ( $1 \mathrm{~d}, 3 \mathrm{~d}, 5 \mathrm{~d})$ and after (post) training camp. Serum scavenging activity against superoxide anion did not change in either group.

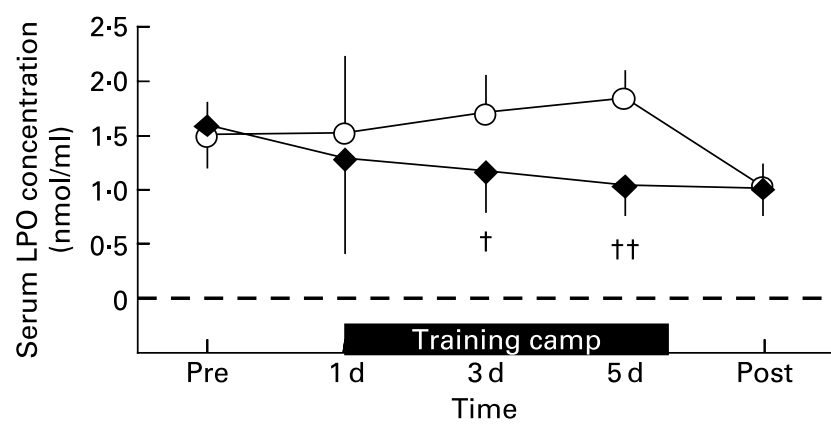

Fig. 4. Serum lipid peroxide (LPO) concentration before (pre), during ( $1 \mathrm{~d}, 3 \mathrm{~d}$, $5 \mathrm{~d})$ and after (post) training camp (- - , coenzyme $\mathrm{Q}_{10} ;-\bigcirc-$, placebo). Values are means and standard deviations. Mean values were significantly differences between coenzyme $Q_{10}$ and placebo groups: $\uparrow P<0.05 ; \dagger+P<0.01$.

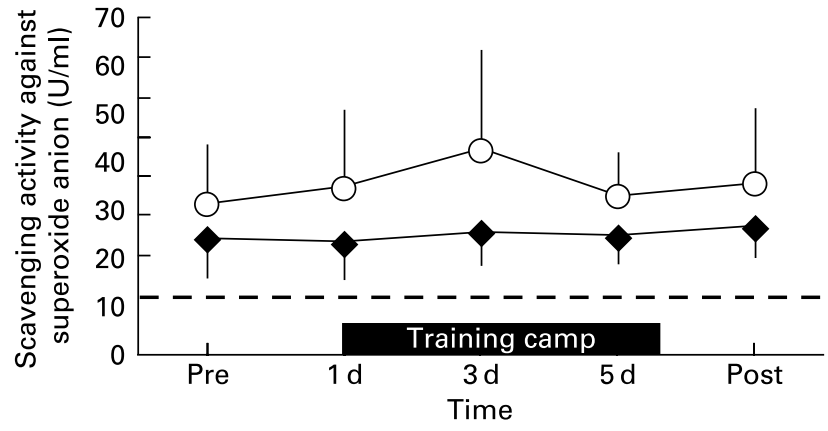

Fig. 5. Scavenging activity against superoxide anion before (pre), during $(1 \mathrm{~d}, 3 \mathrm{~d}, 5 \mathrm{~d})$ and after (post) training camp (- - , coenzyme $\mathrm{Q}_{10}$; $-\mathrm{O}$, placebo). Values are means and standard deviations.

\section{Discussion}

The aim of the present study was to determine the effect of $\mathrm{CoQ}_{10}$ supplementation exercise-induced muscular injury and oxidative stress in kendo athletes during a training camp. The study revealed that $\mathrm{CK}$ activity and $\mathrm{Mb}$ concentration were lower in the $\mathrm{CoQ}_{10}$ group compared with the placebo group. This finding, which is novel, is important because it indicates that supplementation of $\mathrm{CoQ}_{10}$ is useful for reducing exercise-induced muscle damage in athletes. It has been reported that oral administration of $\mathrm{CoQ}_{10}$ increases plasma and skeletal muscle levels of $\mathrm{CoQ}_{10}{ }^{(22,25)}$. In the present study, after 2 weeks of supplementation, serum concentrations of $\mathrm{CoQ}_{10}$ significantly increased only in the $\mathrm{CoQ}_{10}$ group, and the serum $C_{0} Q_{10}$ level remained stable during administration (see Fig. 1). CoQ 10 supplementation $(300 \mathrm{mg} / \mathrm{d})$ for 2 weeks resulted in a 4-fold increase of serum $\mathrm{CoQ}_{10}$ concentration compared with pre level. This result is consistent with that of a previous study ${ }^{(22)}$.

$\mathrm{CK}$ and $\mathrm{Mb}$ have been the most commonly used markers of skeletal muscle damage ${ }^{(26,27)}$. They represent a proxy marker of damage to the muscle cell membrane ${ }^{(26,27)}$. In the present study, serum CK activity in the placebo group significantly increased by 5 -fold during the training camp (see Fig. 2). Also, in the placebo group, serum $\mathrm{Mb}$ concentration significantly increased by $7 \cdot 7$-fold during the training camp (see Fig. 3). The increases of serum $\mathrm{CK}$ and $\mathrm{Mb}$ in the present study indicated that kendo training camp causes muscular injury. $\mathrm{CK}$ and $\mathrm{Mb}$ are indirect markers of muscle damage. Further work involving more direct measures of muscle damage (e.g. electron micrographs) is necessary.

Other studies have investigated the effect of $\mathrm{CoQ}_{10}$ supplementation on exercise-induced muscle damage in both rats ${ }^{(17)}$ and in human subjects ${ }^{(28)}$. CoQ 10 supplementation attenuates CK activity following downhill running in rats ${ }^{(17)}$, but not in human subjects following a marathon $\operatorname{run}^{(28)}$. The difference in results between the previous human study ${ }^{(28)}$ and the present study may be attributable to the intake of $\mathrm{CoQ}_{10}$. In the previous study by Kaikkonen et al. ${ }^{(28)}$, the intake of $\mathrm{CoQ}_{10}$ was $90 \mathrm{mg}$ daily. On the other hand, the intake of $\mathrm{CoQ}_{10}$ in the current study was $300 \mathrm{mg}$ daily. Therefore, there is a possibility that exercise-induced muscular injury was not reduced because the intake of $\mathrm{CoQ}_{10}$ necessary to increase the tissue (muscle) $\mathrm{CoQ}_{10}$ concentrations was low in the previous human study. $\mathrm{CoQ}_{10}$ stabilizes the structure of 
Table 2. Changes of leucocyte (WBC), neutrophil and monocyte count before (pre), during (1 d, $3 \mathrm{~d}, 5 \mathrm{~d})$ and after (post) training camp†

(Mean values and standard deviations)

\begin{tabular}{|c|c|c|c|c|c|c|c|c|c|c|c|}
\hline & \multirow[b]{2}{*}{ Study groups } & \multicolumn{2}{|c|}{ Pre } & \multicolumn{2}{|c|}{$1 d$} & \multicolumn{2}{|c|}{$3 d$} & \multicolumn{2}{|c|}{$5 d$} & \multicolumn{2}{|c|}{ Post } \\
\hline & & mean & SD & mean & SD & mean & SD & mean & SD & mean & SD \\
\hline \multirow[t]{2}{*}{ WBC $(/ \mu l)$} & $\mathrm{CoQ}_{10}$ & 5580 & 1526 & 5318 & 1633 & 6926 & 1261 & 6936 & 1130 & 4928 & 601 \\
\hline & Placebo & 5938 & 1195 & 6237 & 2358 & $8967^{\star \star}$ & 1328 & 7839 & 1117 & 5950 & 1423 \\
\hline \multirow[t]{2}{*}{ Neutrophils $(/ \mu \mathrm{l})$} & $\mathrm{CoQ}_{10}$ & 3281 & 1385 & 3199 & 1623 & $5184^{\star *}$ & 1183 & $4767^{*}$ & 1102 & 2667 & 678 \\
\hline & Placebo & 3442 & 956 & 4079 & 1866 & $6886^{\star *}$ & 901 & $5523^{*}$ & 1206 & 3656 & 1243 \\
\hline \multirow[t]{2}{*}{ Monocytes $(/ \mu \mathrm{l})$} & $\mathrm{CoQ}_{10}$ & 283 & 111 & 241 & 73 & 269 & 60 & 344 & 66 & 272 & 119 \\
\hline & Placebo & 329 & 891 & 318 & 137 & 403 & 153 & 430 & 96 & 313 & 112 \\
\hline
\end{tabular}

CoQ 10 , coenzyme $Q_{10}$.

Mean values were significantly different from pre: ${ }^{\star} P<0.05$; ${ }^{\star *} P<0.01$.

$\dagger$ For details of subjects and procedures, see Materials and methods.

cell membrane phospholipids ${ }^{(29,30)}$ and protects cultured skeletal muscle cells from electrical stimulation-induced muscular cell injury ${ }^{(18)}$. Bello et al. ${ }^{(31)}$ have reported that oral supplementation with $\mathrm{CoQ}_{10}$ significantly increases the $\mathrm{CoQ}_{10}$ count of cell membranes. Therefore, $\mathrm{CoQ}_{10}$ supplementation may reduce exercise-induced muscular injury by raising $\mathrm{CoQ}_{10}$ concentration in muscle cell membranes and stabilizing the cell membrane.

Jackson et al. ${ }^{(32)}$ indicated that muscle damage is associated with an increase in muscle ROS generation. After exercise leading to muscle damage, inflammatory cells, mainly neutrophils and macrophages, infiltrate damaged skeletal muscle and initiate phagocytosis of injured tissue via their arsenal of $\operatorname{ROS}^{(33)}$. They sometimes even release ROS into healthy bystander tissues ${ }^{(34)}$. Therefore, ROS released from inflammatory cells may cause oxidative damage to muscle cell membranes ${ }^{(35)}$. Because $\mathrm{CoQ}_{10}$ is located in membranes in close proximity to unsaturated lipid chains, it acts as a primary scavenger of $\operatorname{ROS}^{(36)}$ and prevents lipid peroxidation ${ }^{(1)}$. In the present study, serum LPO concentration did not change in either group although LPO in the $\mathrm{CoQ}_{10}$ group was lower than in the placebo group (see Fig. 4). Therefore, the effect of $\mathrm{CoQ}_{10}$ supplementation on exercise-induced oxidative stress in athletes was unclear in the current study. $\mathrm{CoQ}_{10}$ may have a greater effect on oxidative stress within skeletal muscle. Other data indicate a possible relationship between infiltration of inflammatory cells and oxidative stress in response to contraction-induced muscle injury ${ }^{(37)}$. Thus, future research could address the effect of $\mathrm{CoQ}_{10}$ supplementation on oxidative damage within skeletal muscle.

ROS produced by neutrophils contribute to muscle damage and circulating neutrophils increase after exercise leading to muscle damage ${ }^{(27,36)}$. However, the influence of oral $\mathrm{CoQ}_{10}$ supplementation on the changes in neutrophil counts after exercise leading to muscle damage is currently unknown. The present study indicates that $\mathrm{CoQ}_{10}$ supplementation had no influence on changes in neutrophil counts after exercise resulting in muscle damage. Other research has reported that $\mathrm{CoQ}_{10}$ treatment attenuated neutrophil oxidative activity ${ }^{(38)}$. Therefore, future studies could examine whether $\mathrm{CoQ}_{10}$ supplementation scavenges the ROS produced by neutrophils that have migrated to the site of injury in skeletal muscle.

The effect of $\mathrm{CoQ}_{10}$ supplementation on antioxidant capacity in serum was determined by ESR with a spin-trapping technique in the present study. Since the superoxide anion scavenging activity in both groups did not change during training camp (see Fig. 5), it is difficult to assess the effect of $\mathrm{CoQ}_{10}$ on scavenging activity. In the present study, the superoxide anion scavenging activity was measured in blood and not in skeletal muscle. Tanabe et al. ${ }^{(24)}$ demonstrated that exercise training increases the superoxide anion scavenging activity in skeletal muscle, as determined by ESR with a spin-trapping technique. In addition, Zhou et al. ${ }^{(39)}$ showed that $\mathrm{CoQ}_{10}$ can directly scavenge hydroxyl radicals from the Fenton reaction, but not superoxide anion radicals from the xanthine/xanthine oxidase system. Hydroxyl radicals have the potential to react with and damage most cellular targets including lipids, proteins and DNA. Hydroxyl radicals are not eliminated by antioxidant enzymes in the cell, but by non-enzymic antioxidants such as $\mathrm{CoQ}_{10}$. Future investigations might consider examining the effect of $\mathrm{CoQ}_{10}$ supplementation on scavenging activity against superoxide anion and the production of hydroxyl radicals in skeletal muscle.

As outlined earlier, blood markers of muscle injury and oxidative stress do not necessarily reflect what events are occurring locally within skeletal muscle during exercise. Because the subjects in the present study were athletes, it was difficult to obtain skeletal muscle samples. A detailed study using human skeletal muscles and/or animal studies are needed in future research. The present study is valid as an initial step to determine the effects of $\mathrm{CoQ}_{10}$ supplementation on exercise-induced muscular injury in athletes.

\section{Conclusion}

In summary, we showed that supplementation of $\mathrm{CoQ}_{10}$ reduced serum $\mathrm{CK}$ activity and $\mathrm{Mb}$ concentration in collegiate kendo athletes during training camp. Our data indicated that muscular injury in these collegiate athletes was attenuated by $\mathrm{CoQ}_{10}$ supplementation. Thus, the present results support the notion that $\mathrm{CoQ}_{10}$ supplementation is useful for reducing muscular injury in athletes.

\section{Acknowledgements}

We thank Kaneka Corp. for their generous gift of $\mathrm{CoQ}_{10}$. We also thank R. DiGovanni (Waseda University, Japan) and 
Jonathan Peake (University of Queensland, Australia) for careful review of the manuscript. None of the authors had a conflict of interest.

\section{References}

1. Turunen M, Olsson J \& Dallner G (2004) Metabolism and function of coenzyme Q. Biochim Biophys Acta 1660, 171-199.

2. Ernster L \& Dallner G (1995) Biochemical, physiological and medical aspects of ubiquinone function. Biochim Biophys Acta 1271, 195-204.

3. Forsmark-Andree P, Dallner G \& Ernster L (1995) Endogenous ubiquinol prevents protein modification accompanying lipid peroxidation in beef heart submitochondrial particles. Free Radic Biol Med 19, 749-757.

4. Kagan V, Serbinova E \& Packer L (1990) Antioxidant effects of ubiquinones in microsomes and mitochondria are mediated by tocopherol recycling. Biochem Biophys Res Commun 169, $851-857$.

5. Lass A \& Sohal RS (1998) Electron transport-linked ubiquinone-dependent recycling of alpha-tocopherol inhibits autooxidation of mitochondrial membranes. Arch Biochem Biophys 352, 229-236.

6. Mohr D, Bowry VW \& Stocker R (1992) Dietary supplementation with coenzyme $\mathrm{Q}_{10}$ results in increased levels of ubiquinol-10 within circulating lipoproteins and increased resistance of human low-density lipoprotein to the initiation of lipid peroxidation. Biochim Biophys Acta 1126, 247-254.

7. Weber C, Bysted A \& Holmer G (1996) The coenzyme $Q_{10}$ content of the average Danish diet. Int J Vitam Res 67, 123-129.

8. Hosoe K, Kitano M, Kishida H, Kubo H, Fujii K \& Kitahara M (2007) Study on safety and bioavailability of ubiquinol (Kaneka $\mathrm{QH})$ after single and 4-week multiple oral administration to healthy volunteers. Regul Toxicol Pharmacol 47, 19-28.

9. Sjodin B, Hellsten Westing Y \& Apple FS (1990) Biochemical mechanisms for oxygen free radical formation during exercise. Sports Med 10, 236-254.

10. McArdle A, van der Meulen JH, Catapano M, Symons MC, Faulkner JA \& Jackson MJ (1999) Free radical activity following contraction-induced injury to the extensor digitorum longus muscles of rats. Free Radic Biol Med 26, 1085-1091.

11. Peake J, Nosaka K \& Suzuki K (2005) Characterization of inflammatory responses to eccentric exercise in humans. Exerc Immunol Rev 11, 64-85.

12. Finaud J, Lac G \& Filaire E (2006) Oxidative stress: relationship with exercise and training. Sports Med 36, 327-358.

13. Radak Z, Pucsok J, Mecseki S, Csont T \& Ferdinandy P (1999) Muscle soreness-induced reduction in force generation is accompanied by increased nitric oxide content and DNA damage in human skeletal muscle. Free Radic Biol Med 26, 1059-1063.

14. Banerjee AK, Mandal A, Chanda D \& Chakraborti S (2003) Oxidant, antioxidant and physical exercise. Mol Cell Biochem 253, 307-312

15. Kumar CT, Reddy VK, Prasad M, Thyagaraju K \& Reddanna P (1992) Dietary supplementation of vitamin E protects heart tissue from exercise-induced oxidant stress. Mol Cell Biochem 111, 109-115.

16. Mastaloudis A, Morrow JD, Hopkins DW, Devaraj S \& Traber MG (2004) Antioxidant supplementation prevents exerciseinduced lipid peroxidation, but not inflammation, in ultramarathon runners. Free Radic Biol Med 36, 1329-1341.

17. Shimomura Y, Suzuki M, Sugiyama S, Hanaki Y \& Ozawa T (1991) Protective effect of coenzyme $\mathrm{Q}_{10}$ on exercise-induced muscular injury. Biochem Biophys Res Commun 176, 349-355.
18. Okamoto T, Kubota N, Takahata K, Takahashi T, Goshima K \& Kishi T (1995) Protective effect of coenzyme $\mathrm{Q}_{10}$ on cultured skeletal muscle cell injury induced by continuous electric field stimulation. Biochem Biophys Res Commun 216, 1006-1012.

19. Imai H, Hayashi $T$, Negawa $T$, Nakamura K, Tomida M, Koda K, Tajima T, Koda Y, Suda K \& Era S (2002) Strenuous exercise-induced change in redox state of human serum albumin during intensive kendo training. Jpn J Physiol 52, 135-140.

20. Kon M, Kimura F, Tanimura Y, Shimizu K \& Kono I (2006) The influence of coenzyme $\mathrm{Q}_{10}$ ingestion on hemolysis in college kendo athletes at a training camp. Sport Sciences 3, 78-84.

21. Kon M, Nakamura K, Natsui H, Kimura F, Lee H, Akama T \& Kono I (2006) Changes in serum haptoglobin in college kendo athletes at a training camp. Res $J$ Budo 39, 1-8.

22. Dill DB \& Costill DL (1974) Calculation of percentage changes in volumes of blood, plasma, and red cells in dehydration. $J$ Appl Physiol 37, 247-248.

23. Ikematsu H, Nakamura K, Harashima S, Fujii K \& Fukutomi N (2006) Safety assessment of coenzyme $\mathrm{Q}_{10}$ (Kaneka $\mathrm{Q}_{10}$ ) in healthy subjects: a double-blind, randomized, placebo-controlled trial. Regul Toxicol Pharmacol 44, 212-218.

24. Tanabe K, Masuda K, Hirayama A, Nagase S, Kono I \& Kuno S (2006) Effect of spontaneous exercise on antioxidant capacity in rat muscles determined by electron spin resonance. Acta Physiol (Oxf) 186, 119-125.

25. Kwong LK, Kamzalov S, Rebrin I, Bayne AC, Jana CK, Morris P, Forster MJ \& Sohal RS (2002) Effects of coenzyme Q (10) administration on its tissue concentrations, mitochondrial oxidant generation, and oxidative stress in the rat. Free Radic Biol Med 33, 627-638.

26. Koutedakis Y, Raafat A, Sharp NC, Rosmarin MN, Beard MJ \& Robbins SW (1993) Serum enzyme activities in individuals with different levels of physical fitness. J Sports Med Phys Fitness 33, 252-257.

27. Peake JM, Suzuki K, Wilson G, Hordern M, Nosaka K, Mackinnon L \& Coombes JS (2005) Exercise-induced muscle damage, plasma cytokines, and markers of neutrophil activation. Med Sci Sports Exerc 37, 737-745.

28. Kaikkonen J, Kosonen L, Nyyssonen K, Porkkala-Sarataho E, Salonen R, Korpela H \& Salonen JT (1998) Effect of combined coenzyme Q10 and d-alpha-tocopheryl acetate supplementation on exercise-induced lipid peroxidation and muscular damage: a placebo-controlled double-blind study in marathon runners. Free Radic Res 29, 85-92.

29. Kambara N, Takagi K, Satake T, Sugiyama S \& Ozawa T (1983) Mechanism responsible for endotoxin-induced lung microsomal dysfunction in rats. Lung 161, 361-368.

30. Nagai S, Miyazaki Y, Ogawa K, Satake T, Sugiyama S \& Ozawa $\mathrm{T}$ (1985) The effect of Coenzyme $\mathrm{Q}_{10}$ on reperfusion injury in canine myocardium. $J$ Mol Cell Cardiol 17, 873-884.

31. Bello RI, Gomez-Diaz C, Buron MI, Alcain FJ, Navas P \& Villalba JM (2005) Enhanced anti-oxidant protection of liver membranes in long-lived rats fed on a coenzyme $\mathrm{Q}_{10}$-supplemented diet. Exp Gerontol 40, 694-706.

32. Jackson MJ, Edwards RH \& Symons MC (1985) Electron spin resonance studies of intact mammalian skeletal muscle. Biochim Biophys Acta 847, 185-190.

33. Moncada S \& Higgs A (1993) The L-arginine-nitric oxide pathway. N Engl J Med 329, 2002-2012.

34. Cheeseman KH \& Slater TF (1993) An introduction to free radical biochemistry. Br Med Bull 49, 481-493.

35. Ji LL (1999) Antioxidants and oxidative stress in exercise. Proc Soc Exp Biol Med 222, 283-292.

36. Close GL, Ashton T, Cable T, Doran D, Noyes C, McArdle F \& MacLaren DP (2005) Effects of dietary carbohydrate on delayed onset muscle soreness and reactive oxygen species after contraction induced muscle damage. Br J Sports Med 39, 948-953. 
37. Kon M, Tanabe K, Lee H, Kimura F, Akimoto $\mathrm{T} \&$ Kono I (2007) Eccentric muscle contractions induce greater oxidative stress than concentric contractions in skeletal muscle. Appl Physiol Nutr Metab 32, 273-281.

38. Dlugosz A, Kuzniar J, Sawicka E, Marchewka Z, LembasBogaczyk J, Sajewicz W \& Boratynska M (2004) Oxidative stress and coenzyme $\mathrm{Q}_{10}$ supplementation in renal transplant recipients. Int Urol Nephrol 36, 253-258.

39. Zhou M, Zhi Q, Tang Y, Yu D \& Han J (1999) Effects of coenzyme $\mathrm{Q}_{10}$ on myocardial protection during cardiac valve replacement and scavenging free radical activity in vitro. $J$ Cardiovasc Surg (Torino) 40, 355-361. 